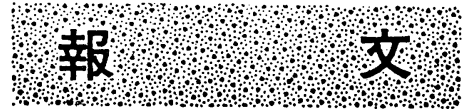

\title{
はちみつ中の菌類分布について
}

(昭和 49 年 7 月 11 日受理)

$\begin{array}{lll}\text { 山 崎 幹夫*1 } & \text { 堀 江 義 }{ }^{* 1} & \text { 宇田川俊一*1 } \\ \text { 越後多嘉志 }^{* 2} & \text { 君 政 子*2 }\end{array}$

\section{Mycoflora of Honey}

\section{Mikio YAMAZAKI*1, Yoshikazu HoRIE*1, Shun-ichi UdAGAWA*1, Takashi ECHIGO*2 and Masako KIMI*2}

(*1Research Institute for Chemobiodynamics, Chiba University: Izumi-cho, Narashino, Chiba; *2Department of Agricultural Chemistry, Tamagawa - University: Tamagawa-Gakuen, Machida, Tokyo)

\begin{abstract}
Mycological survey of honey, 23 samples of domestic and imported, was carried out and Chaetomium, Eurotium, Aspergillus, Cladosporium, Penicillium and others were found and isolated less than a great dominant of the yeast. In media added with several concentrations of glucose or sucrose and even in honey itself, growth of the isolates, for example E. repens, E. rubrum, A. awamori, C. cladosporioides and $P$. waksmani, was recognized. In conclusion, "inhibitory effect" of honey for the fungal growth is thought to be due not only to the high concentration of sugar and low $\mathrm{pH}$ but also to the prior dominant growth of the yeast in honey.
\end{abstract}

(Received July 11, 1974)

はちみつ中の微生物分布については，すでに二，三 の報告があるが，それらの大部分は Saccharomyces， Candida 属などを主とする酵母関するものであり ${ }^{1)}$, 酵母を除く他の菌類に関する研究はほとんどみられない のが現状である。

著者らは，はちみつより菌類の分離を試み，それら菌 類のはらみつ中にお沙る菌類フローラの特性およびはち みつの菌類による污染の実態と，はちみつより分離した 主な菌類の高糖濃度に批方生育につき検討したので報 告する.

\section{実験材料および方法}

\section{1. 試料の採集}

実験に供したはちみつはすべて玉川大学農学部食品製

*1 千葉大学生物活性研究所：千葉県習志野市泉町 39-1

*2 玉川大学農学部：東京都町田市玉川学園 6-1-1
造研究室を通じて入手した。1972年産はちみつ10試料, 1973年産はちみつ 7 試料, 合計 17 試料の国内産のはちみ つ (Table 1) と, 比較のため 1973 年に入手した外国産 の輸入はちみつ 6 試料 (Table 2), 合計 23 試料を実験に 供した.

すなわち1972年国内産はちみつの採集地は秋田県, 鳥 取県, 北海道, 青森県, 長野県, 東京都, 久つ源植物は トチ, レンゲソウ, アカシア, シナノキ, アブラナ, 糖 濃度は73.4 80.1\%であった。1973年国内産はちみつの 採集地崠東京都, 長野県, 鳥取県, 岡山県, 秋田県, 又 つ源植物はレンゲソウ,アカシア, 糖濃度は73.6 79.4\% であった。

外国産はちみつは，中国，カナダ，アルゼンチン，ス ペインなどより輸入されたもので, みつ源植物はレンゲ ソウ，クローバー，オレンジ，その他。桾濃度は72.5 81.4\%であった。 
Table 1. List of Samples (Domestic Honey)

\begin{tabular}{|c|c|c|c|c|}
\hline Sample no. & Date of collection & Locality & Origin & $\stackrel{\text { Sugar }}{\text { concentration }(\%)}$ \\
\hline 2 & 1972. 5. 27 & Akita & Horse chesnut & 80.1 \\
\hline 41 & 5. 4 & Tottori & Chinese milk vetch & - \\
\hline 42 & 6. 99 & Akita & Acacia & 76.7 \\
\hline 43 & 6. 29 & Hokkaido & Linden & 77.2 \\
\hline 44 & 5. 27 & Aomori & Rapeseed & 73.4 \\
\hline 45 & 5. 4 & Tottori & Chinese milk vetch & 78.5 \\
\hline 46 & 5. 4 & Tottori & Chinese milk vetch & 79.4 \\
\hline 47 & 5. - & Nagano & - & - \\
\hline 49 & 5. 13 & Tokyo & - & 79.0 \\
\hline 50 & 1973. 5. 11 & Tokyo & - & 78.4 \\
\hline 51 & 4. - & Nagasaki & Chinese milk vetch & 76.0 \\
\hline 60 & 4. 29 & Nagasaki & - & 74.4 \\
\hline 61 & 5. 5 & Tottori & Chinese milk vetch & 79.2 \\
\hline 62 & 5. 17 & Okayama & Chinese milk vetch & 79.4 \\
\hline 63 & 6. 27 & Akita & Acacia & 73.6 \\
\hline 64 & 6. - & Akita & Acacia & 73.1 \\
\hline
\end{tabular}

Table 2. List of Samples (Imported Honey)

\begin{tabular}{|c|c|c|c|c|}
\hline Sample no. & Date of collection & Locality & Origin & $\begin{array}{c}\text { Sugar } \\
\text { concentration }(\%)\end{array}$ \\
\hline 53 & 1973.6 . & China & Chinese milk vetch & 79.1 \\
\hline 54 & 6 & Canada & Clover & 72.5 \\
\hline 55 & - & - & - & 81.4 \\
\hline 56 & 6. & Argentina & $\longrightarrow$ & 79.5 \\
\hline 57 & - & - & - & 79.6 \\
\hline 58 & - & Spain & Orange & 80.6 \\
\hline
\end{tabular}

\section{2. 菌の分離法}

はちみつよりの菌類の分離培地は，はちみつ中の主要 な有機酸とされるグルコン酸を用いて，はちみつの $\mathrm{pH}$ に近い $\mathrm{pH} 3.8$ 前後淍整した M70Y (ショ糖 $700 \mathrm{~g}$, 麦芽エキス $20 \mathrm{~g}$ ，酵母エキス $5 \mathrm{~g}$ ，寒天 $20 \mathrm{~g}$ ，水 1000 $\mathrm{ml}$ ) および $\mathrm{pH}$ 無調整の M70Y, M40Y (ショ糖 $400 \mathrm{~g}$, 麦芽エキス $20 \mathrm{~g}$ ，酵母エキス $5 \mathrm{~g}$ ，寒天 $20 \mathrm{~g}$ ，水 1000 $\mathrm{ml}), \quad$ クロランェニコール添加バレイショ・グルコー ス寒天 (バレイショ $300 \mathrm{~g}$ の煮汁, グルコース $20 \mathrm{~g}$, 寒 天 $20 \mathrm{~g}$, 水 $1000 \mathrm{ml}$, クロラムフェニコール $100 \mathrm{mg}$ ) の 4 種類を用いはちみつ試料につき各 5 枚ずつの隇菌ぺ トリザラに流し, 固めて平板とした後, はちみつ 1 滴 （約 $50 \mathrm{mg}$ )を滴下し, 隇菌ガラス棒で平板上に均一に広 げ，250で 2 週間培養を行い，出現したコロニーより，

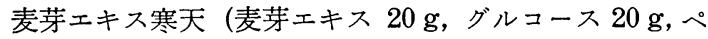
プトン $1 \mathrm{~g}$, 寒天 $20 \mathrm{~g}$, 水 $1000 \mathrm{ml}), \mathrm{M} 40 \mathrm{Y}, シ ョ$ 糖添 加 Czapek 寒天 (ショ糖 $200 \mathrm{~g}, \mathrm{NaNO}_{3} 3 \mathrm{~g}, \mathrm{~K}_{2} \mathrm{HPO}_{4}$
$1 \mathrm{~g}, \mathrm{MgSO}_{4} \cdot 7 \mathrm{H}_{2} \mathrm{O} 0.5 \mathrm{~g}, \mathrm{FeSO}_{4} \cdot 7 \mathrm{H}_{2} \mathrm{O} 0.01 \mathrm{~g}$, 寒天 15 $\mathrm{g}$, 水 $1000 \mathrm{ml})$, クロラムフェニュール添加バレイショ・ グルコース寒天, クロラムフェニコール添加バレイシ ョ・ニンジン寒天 (PCA と略, バレイショ $15 \mathrm{~g},=ン$ ジン $15 \mathrm{~g}$ の煮汁, 水 $1000 \mathrm{ml}$, クロラムフェニコール $100 \mathrm{mg}$ ) の各斜面培地を適宜に用いて釣菌分離し, 以後 の同定に供した。

3. 菌の同定

分離した菌類の同定は, Aspergillus, Penicillium 属に関しては標準 Czapek 寒天および標準麦芽エキ ス寒天の平板に接種 し，巨大コロニーを形成させ， Aspergillus 属の菌は Raper と Fennell ${ }^{2)}$,Penicillium 属の菌は Raper と Thom らの成書 ${ }^{3}$ を参考として同 定を行い，その他の不完全菌類は，バレイショ・ニンジ ン寒天，バレイショ・グルコース寒天を主として用い, Barnett $^{4)}$, Barron $^{5)}$, Arx $^{(8)}$ および Subramanian ${ }^{7)} ら の$ 成書を参考として同定を行った.また，子のう菌類の同定 
Table 3. Frequency of Molds Isolated from Domestic Samples

\begin{tabular}{|c|c|c|c|c|c|c|c|c|c|c|c|}
\hline \multirow{2}{*}{ Genera and species } & \multicolumn{6}{|c|}{1972} & \multicolumn{5}{|c|}{1973} \\
\hline & 2 & 41 & 42 & 45 & 46 & 47 & 50 & 60 & 61 & 62 & 63 \\
\hline \multicolumn{12}{|l|}{ Ascomycetes } \\
\hline Ascosphaera apis & & & & & + & & & & & & + \\
\hline Eurotium amstelodami & & & & & + & & & & & & \\
\hline \multicolumn{12}{|l|}{ Deuterømycetes } \\
\hline Aspergillus & & & + & & + & & & & & & \\
\hline Cladosporium & + & + & & + & + & + & & & & & \\
\hline Paecilomyces & & & + & & + & & + & & & & \\
\hline Penicillium & & & & & + & & 世 & 世 & 册 & 冊 & W \\
\hline Scopulariopsis & & & & & + & + & & & & & \\
\hline
\end{tabular}

W, H, very abundant; H, abundant; +, common.

は, Eurotium 属の場合20\%ショ糖添加 Czapek 寒天, $20 \%$ ショ糖添加麦芽エキス寒天を主として用い， Raper と Fennell の成書 2 を参考とし，また，Chaetomium 属の菌はセルロース寒天, バレイショ・ニンジン寒天, オートミール寒天を主として用い, $\mathrm{Ames}^{8)}$, Seth らの 成書および Udagawa ${ }^{10)}$ その他の文献 ${ }^{11)}$ を参考とし, その他の子のう菌は, バレイショ・ニンジン寒天,オー トミール寒天などを適宜に用いて子のら殼を形成させ，

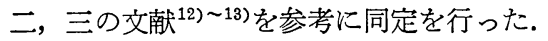

\section{4. 分離菌の各糖濃度における生育の影響}

はちみつより分離された主要菌類の生育における糖濃 度の影響と限界，生育の状態などを知るため，下記の害 験を行った。

方法としては，基本培地として麦芽・酵母エキス寒天 (麦芽エキス $20 \mathrm{~g}$, 酵母エキス $5 \mathrm{~g}$, 寒天 $20 \mathrm{~g}$, 水 1000 $\mathrm{ml}$ ) にグルコースおよびショ糖を各 $0 ， 20 ， 40,60$, $80,100 \% *(\mathrm{w} / \mathrm{v})$ 加えた $\mathrm{pH}$ 無調整の培地と, グルコ ン酸で, $\mathrm{pH} 3.8$ 前後に調整した培地の平板に主要な菌 を接種し， $25^{\circ}$ で 2 週間培養を行い，コロニーの直径を 測定しまた，そのときのコロニーの状態を観察した。 測定には各ペトリザラ 5 枚を使用し，その平均を示し た.

\section{結 果}

\section{1. 菌類の分布}

国内産のはちみつよりの菌類の出現頻度は Table 3 に 示したように比較的低かった。1972年産の国内産はちみ つよりは 10 試料中 6 試料より菌類の出現を見た. 出現し た菌類は子のう菌では Ascosphaera apis, Eurotium amstelodami の 2 種, 不完全菌では, Aspergillus, Cladosporium, Paecilomyces, Penicillium, Scopulariopsis 属であった.この内 Cladosporium は,

*糖 $1000 \mathrm{~g}$ に培地を加え $1000 \mathrm{ml}$ に調整したものを 便宜的に $100 \%$ とした。
Table 4. Frequency of Molds Isolated from Imported Samples

Sample no.

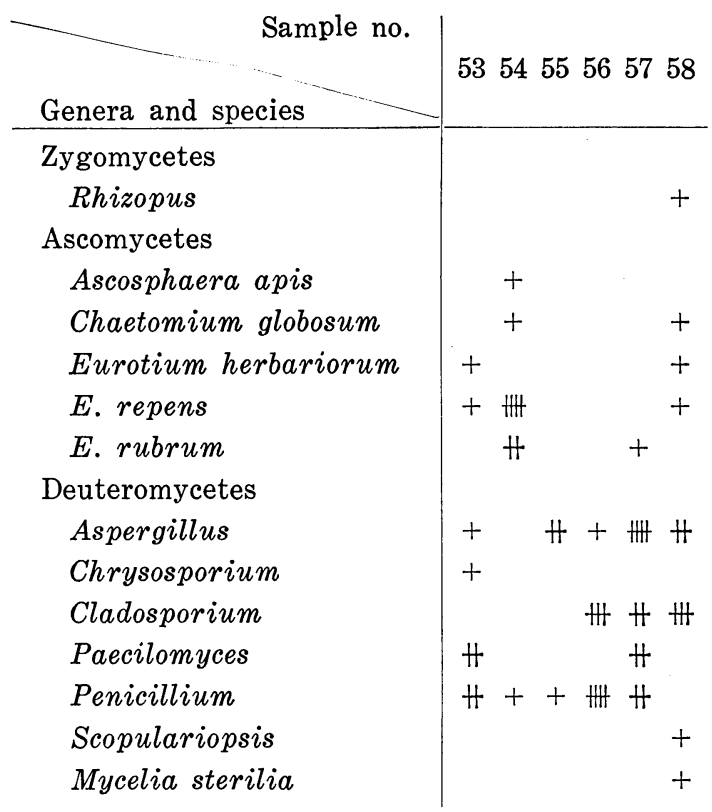

W, $\mathrm{H}$, very abundant; H, abundant; +, common.

量的には少ないが，5試料にわたって出現した，1973年 産の国内産はりみつ 7 試料中 5 試料より菌類の出現を見 たが, 出現した菌類は Paecilomyces, Penicillium の 2 属の菌の夕であった。ただし,Penicillium 属の菌 は量的にも，また，試料数も比較的多く出現した。

今回 Ascosphaera apis が少数であったが出現した ことは興味深い.この菌は, Mossen ${ }^{14)}$ によってヨーロ ッパ， Baker ら ${ }^{15)}$ とって北米に执いて，はちみつの 幼虫を “Chalk broad” (いわゆる“ミイラ化”) させる はちみつの病原菌として報告されており,この菌の生 
Table 5. Aspergilli Isolated from Honey, Samples

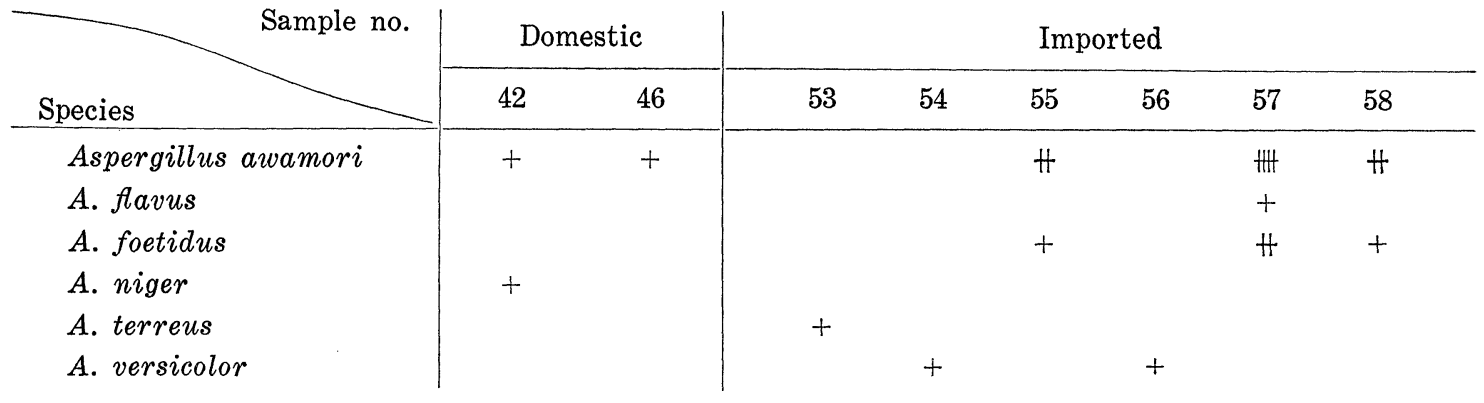

H, very abundant; $\#$, abundant; + , common.

Table 6. Penicillia Isolated from Domestic Honey

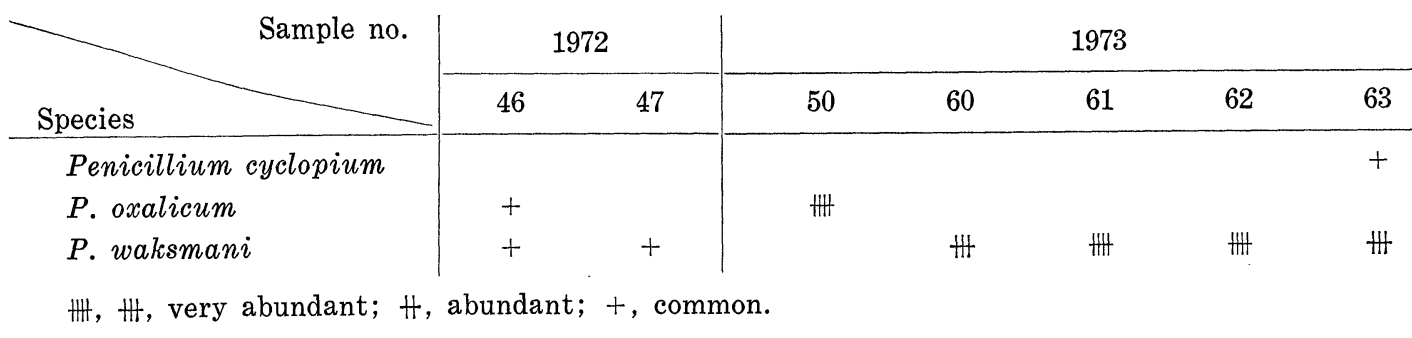

Table 7. Penicillia Isolated from Imported Honey

\begin{tabular}{|c|c|c|c|c|c|}
\hline $\begin{array}{ll} & \text { Sample no. } \\
\text { Species } & \end{array}$ & 53 & 54 & 55 & 56 & 57 \\
\hline Penicillium cyclopium & + & + & + & + & H \\
\hline P. implicatum & + & & & & \\
\hline P. lividum & & & & + & \\
\hline P. rugulosum & & & & + & \\
\hline P. waksmani & + & + & & m & \\
\hline
\end{tabular}

冊, very abundant; $\#$, abundant; +, common.

理，生態に関しては多くの研究が報告されている.この 菌はこれまで我が国での分離の報告は無く, 今回の分離 が最初であろらと思われる。

1973年に入手した輸入はちみつは Table 4 に示した ように 6 試料全部より菌類が出現し，その頻度は国内 産はちみつと比較して高く, 分離された菌類は Zygomycetes では Rhizopus 属, Ascomycetes ではAscosphaera apis, Chaetomium globosum, Eurotium herbariorum, E. repens, E. rubrum の 3 属 5 種, 不完全菌は Aspergillus, Chrysosporium, Cladosporium, Paecilomyces, Penicillium, Scopulariopsis の 6 属であった. そのうち比較的出現の頻度の高 かった菌としては, Eurotium, Aspergillus, Cladosporium, Penicillium 属の菌であった。また，国内
産, 輸入品ともに全試料より Saccharomyces を主とし た酵母が多数出現し，これら酵母の出現した量と比較し て，他の菌類の出現頻度は非常に低かった.

Table 3,4 に拉いて比較的出現頻度の高かった菌類 は Aspergillus, Cladosporium, Penicillium の 3 属 に属する菌で, このうち Cladosporium 属に属する菌 はすべて Cladosporium cladosporioides であっだ Aspergillus 属では Table 5 に示したように $A s^{-}$ pergillus awamori, A. flavus, A. foetidus, $A$. niger, A. terreus, A. versicolor の 6 種が出現した. そのうち国内産はちみつより 1972 年産はちみつに $A$. awamori, A. niger の 2 種, 輸入はちみつよりは $A$. awamori, A. flavus, A. foetidus, A. terreus, $A$. versicolor の 5 種が分離された。傾向としては, いわ ゆる “Aspergillus niger グループ” の菌の出現が目 立った.な拉, Aspergillus flavus は aflatoxin $A$, versicolor は sterigmatocystin を生産することで知 られているが，今回分離された菌株には薄層クロマトグ ラフィーを使用した検索の結果, 両マイコトキシンの生 産性は見られなかった。

Penicillium 属に関しては Table 6,7 に示したよ うに, 国内産はちみつょりは, $P$. cyclopium, $P$. oxalicum, P. waksmani の 3 種が分離され, 特に $P$. waksmani の出現が目立った。 この菌は，これまで主 としてしょう油，みそなど塩濃度の高い食品よりの分離 が報告されている。輸入みつよりは P. cyclopium, $P$. 
Table 8. Effect of Glucose Concentration for Linear Growth of Isolated Molds

\begin{tabular}{|c|c|c|c|c|c|c|c|}
\hline \multicolumn{2}{|c|}{ Glucose concentration $(\% \mathrm{w} / \mathrm{v})$} & 0 & 20 & 40 & 60 & 80 & 100 \\
\hline Species & Acid* & \multicolumn{6}{|c|}{ Diameter of colonies $(\mathrm{cm})$} \\
\hline \multirow[t]{2}{*}{ Eurotium repens } & added & 0.5 & 7.4 & 8.5 & 7.6 & 0.9 & nil \\
\hline & no & 2.7 & 7.7 & 8.5 & 8.5 & 5.5 & \pm \\
\hline \multirow[t]{2}{*}{ Eurotium rubrum } & added & 0.1 & 3.9 & 8.5 & 7.6 & + & nil \\
\hline & no & 1.8 & 8.3 & 8.5 & 8.5 & 6.7 & \pm \\
\hline \multirow[t]{2}{*}{ Aspergillus awamori } & added & 8.0 & 8.5 & 8.5 & 7.2 & \pm & nil \\
\hline & no & 6.9 & 8.5 & 8.5 & 8.5 & 2.2 & nil \\
\hline \multirow[t]{2}{*}{ Cladosporium cladosporioides } & added & 1.7 & 1.2 & 0.9 & 0.3 & \pm & nil \\
\hline & no & 3.4 & 6.1 & 6.6 & 5.0 & \pm & nil \\
\hline \multirow[t]{2}{*}{ Penicillium waksmani } & added & 7.5 & 7.3 & 4.7 & 2.3 & \pm & \pm \\
\hline & no & 7.8 & 8.5 & 5.6 & 3.1 & 0.8 & nil \\
\hline
\end{tabular}

* Gluconic acid ( $\mathrm{pH} 3.8)$.

implicatum, P. lividum, P. rugulosum, P. waksmaniの 5 種が分離された.このうちでは $P$. cyclopium と P.waksmani の出現が比較的顕著であった。

\section{2. 各糖濃度における菌類の生育}

1) グルコースの各濃度に括ける生育

はちみつより分離した菌類の中で, 比較的出現頻度の 高かった Eurotium repens, E. rubrum, Aspergillus awamori, Penicillium waksmani, Cladosporium cladosporioides ら5 種の菌類を各濃度のグルコースを 添加した麦芽エキス・酵母エキス寒天に接種生育させ

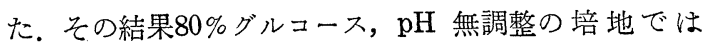
C. cladosporioides 以外はわずかに生育したが，グルコ ン酸で pH 3.8 に調整した培地では，E.repens を除き 明確な生育を示さなかった．をた，C. cladosporioides はグルコン酸で $\mathrm{pH} 3.8$ の寒天上と無調整の寒天上で 生育に著しい差異を示した。結果はまとめて Table 8 に示した。

これらの菌類が $80 \%$ グルコースを添加し, $\mathrm{pH} 3.8$ に 調整した寒天上においては明確な生育を示さなかったの で，スライドカルチャーの手法を利用し，菌の分生子お よび閉子のら殼の形成扣よび形態を調べた。その結果は いずれの菌も分生子拈よび閉子のう殼を十分形成し, 形 態的には普通の培地上で生育したときと変化が認められ なかった。

2) ショ糖の各濃度に打ける生育

次に Eurotium repens, E. rubrum, Aspergillus awamori, Penicillium waksmani, P. cyclopium, Cladosporium cladosporioides などの囷類および Ascosphaera apis を用い，グルコースと同様の実験 をショ糖について実施した。
その結果は, Ascosphaera apis を除く他の菌類はい ずれも $60 \%$ ショ糖を加えた培地でも十分な生育を示し, 結果はグルコースに比べやや高い生育限界濃度を示し た. Eurotium repens, E. rubrum, Aspergillus awamori は80\%ショ糖を加えた培地でも生育し, Penicillium cyclopium, P. waksmani はわずかで あるが生育を示した。 しかし Cladosporium cladosporioides は pH 無調整の培地では生育を示したが， $\mathrm{pH} 3.8$ の培地では生育を示さなかった。 $100 \%$ ショ糖 を添加した培地では Eurotium repens, E. rubrum が生育を示したに過ぎない。

3) はちみつ中での生育状態

次に, 分離したこれら菌類が，はちみつ上で正常に生 育できるかどらかにつき，Eurotium repens， E. rubrum, Aspergillus awamori の3 種の菌を使用 し，スライドカルチャーの手法を用いて調ベた。 その結 果, Eurotium 2 種は分生子および閉子のう殼の両方と も形態的にも正常に生育, 形成され，またAspergillus awamori 女正常の形態の分生子を形成した.この結果 より，これら菌類はある程度の湿地があればはちみつ中 でも十分生育することが推測された。

\section{考察}

以上の結果より, はちみつ中にも酵母以外の菌類がか なり多種にわたって存在していることが確認された。こ れら出現菌類の傾向としては, はちみつの性質上高張性 の菌類および, 高張性の傾向を持った性質の菌類の存在 が予測されたが，今回はらみつ中より分離された菌類 は, Eurotium repens, E. rubrum など Eurotium 属, Aspergillus awamori, A. foetidus, A. niger などのいわゆる Aspergillus niger group のほか, 
Penicillium cylcopium, P. waksmani, Cladosporium cladosporioides などであり, Eurotium 属, Aspergillus niger グループが比較的多く出現したこ とで菌類の存在を確認した。 しかし今回の分離でみつ源 となる花樹に着生および寄生すると思われる植物病原菌 などの菌類がほとんど出現しなかったことは興味ある現 象である。

これらの菌類がはちみつの生産過程のどの段階で活 染, 混入したかについて，酵母についてはこれまでに花 みつよりの遷移などの調査結果が報告されている.今回 分離された菌類の生態と考え併せると, 明確なことはい えないにしても，Ascosphaera apis の様な病原菌は 巣箱などで污染混入したものと考学られ，Eurotium, Aspergillus, Cladosporium, Penicillium 属などの 菌類は，巣箱㧍よび，それ以後の製品化の過程で二次的 に污染したものと考えられる。

はちみつは一般には貯蔵性がよく, 普通の状態では変 質することはないと言われている。ごくまれに発酵や混 入微生物の増殖が見られることもあるが，これは主とし て水分の増加による、例えば高湿度環境中での放置など によって表面の吸湿による糖濃度の低下の結果, 微生物 の増殖が認められることはあるとされる。

今回分離された菌について，グルコース，ショ糖の各 濃度に打ける生育状態を調べた結果は, はちみつより分 離された主要な菌類の多くが，はちみつとほぼ同様の濃 度执よび $\mathrm{pH}$ に拉いても生育出来, またはちみつ自体 中でも発芽, 生育の可能なことを示した. 高張性菌であ るEurotium 属の菌類は当然としても, Penicillium waksmani を除く他の菌も, 糖無添加の培地より 20 , 40\%にショ糖を加えた培地でよい生育を示した。ただし Cladosporium cladosporioides では $\mathrm{pH}$ をグルコン 酸で調整 $(\mathrm{pH} 3.8)$ した培地での生育が著しく悪かっ た. 以上の現象はグルコース添加培地上でも同じように 観察された。 $\mathrm{pH}$ 無調整の培地と $\mathrm{pH} 3.8$ に調整した培 地では，一般に前者に沶いてはるかに生育は良好であっ たが，グルコース培地に比較してショ糖培地ではその差 がそれ注ど顕著でなかったことは興味深い。

以上の結果から考察すると, はらみつが一般に発徽し にくいのは，単に高糖濃度，低 $\mathrm{pH}$ であることが原因で あるばかりでなく，このような条件下では酵母による安 定した優先型環境がつくられ，他の菌類の侵入生育を妨 げていることが考えられるが，このことはさらに検討を 要する問題であろう.

謝辞

本研究に終始御指導を賜わった故宮木高明博士に感謝
します.はらみつの試料入手, 研究の推進に御協力頂い た玉川大学農学部竹中哲夫氏, マイコトキシンの検索に 御協力頂いた千葉大学生物活性研究所前林行雄氏に感謝 します。

文 献

1) Rose, A. H., Harrison, J.S.: "The Yeast" Vol. 3 (1970), Academic Press, London and N. Y.

2) Raper, K. B., Fennel, D. I.: "The Genera Aspergillus" (1965), The Williams \& Wilkins Co., Baltimore.

3) Raper, K. B., Thom, C.: "A Manual of the Penicillia” (1949), The Williams \& Wilkins Co., Baltimore.

4) Barnett, H. L.: "Illustrated Genera of Imperfect Fungi” (1960), Burgess Publ. Co., Minnesota.

5) Barron, G. L.: " The Genera of Hyphomycetes from Soil" (1968), The Williams \& Wilkins Co., Baltimore.

6) von Arx, J.A.: "The Genera of Fungi Sporulating in Pure Culture" (1970), J. Cramer, Germany.

7) Subramanian, C. V.: “Hyphomycetes" (1971), Indian Council of Agricultural Res., New Delhi.

8) Ames, L. M.: "A Monograph of the Chaetomiaceae" (1968), U.S. Army Res. \& Development Ser. 2.

9) Seth, H.K.: "A Monograph of the Genus Chaetomium" (1970), J. Cramer, Germany.

10) Udagawa, S.: J. gen. appl. Microbiol., Tokyo, 6, 223 (1960).

11) Zopf, W.: Nova Acta ksl. Leop. Carol, Deutchen Akademie der Naturforscher XLII, 199 (1881).

12) Spiltoir, C. F., Olive, L. S.: Mycologia, 47, 238 (1955).

13) Malloch, D., Cain, R. F.: Can. J. Bot., 50, 2613 (1972).

14) Maassen, A.: Mitt. Biol. Anst. Land-Fortsn., 16, 51 (1916).

15) Baker, G. M., Torchio, P. F.: Mycologia, 60, 189 (1968). 